across multiple clinical trials (1.3/100 PY [95\% Cl, 0.2-4.8]). In pts at risk for IBD requiring biologic therapy, ADA is a reasonable therapeutic option based on the observed low IBD event rates in ADA clinical trials and its demonstrated efficacy in treating $U C$ and $C D$ pts.

References:

[1] Braun, J. et al., Arthritis \& Rheum, 2007; 57:639-47.

Acknowledgements: AbbVie funded the studies, contributed to their design, and participated in data collection, analysis and interpretation of the data, and in writing, review, and approval of the publication. Medical writing support was provided by Deepa Venkitaramani, PhD, of AbbVie.

Disclosure of Interest: J. R. Curtis Grant/research support from: Amgen, BMS, CORRONA, Crescendo, Janssen, Pfizer, and UCB., Consultant for: Amgen, BMS, CORRONA, Crescendo, Janssen, Pfizer, and UCB., D. Elewaut Grant/research support from: AbbVie, Consultant for: AbbVie, Speakers bureau: AbbVie, S. Chen Shareholder of: AbbVie, Employee of: AbbVie, M. Hojnik Shareholder of: AbbVie, Employee of: AbbVie, N. Naveh Shareholder of: AbbVie, Employee of: AbbVie, J. K. Anderson Shareholder of: AbbVie, Employee of: AbbVie DOI: 10.1136/annrheumdis-2017-eular.2008

\section{FRI0445 FAECAL CALPROTECTIN, BUT NOT ANTI-SACCHAROMYCES CEREVISIAE ANTIBODIES, IS LINKED TO WORSE DISEASE STATUS IN AXIAL SPONDYLOARTHRITIS PATIENTS WITHOUT INFLAMMATORY BOWEL DISEASE: RESULTS FROM THE SPARTAKUS COHORT}

T. Olofsson ${ }^{1}$, E. Mogard ${ }^{1}$, K. Andréasson ${ }^{1}$, J. Marsal ${ }^{2}$, M. Geijer ${ }^{3}$, L.-E. Kristensen ${ }^{1,4}$, E. Lindqvist ${ }^{1}$, J.K. Wallman ${ }^{1} .{ }^{1}$ Department of clinical sciences Lund, Rheumatology: ${ }^{2}$ Department of clinical sciences Lund, Gastroenterology, Lund University, Lund; ${ }^{3}$ Department of Radiology, Faculty of Medicine and Health, Örebro University, Örebro, Sweden: ${ }^{4}$ The Parker Institute, Department of Rheumatology, Copenhagen University Hospital, Frederiksberg and Bispebjerg, Copenhagen, Denmark

Background: Inflammatory bowel disease (IBD) is a common comorbidity in axial spondyloarthritis.

Objectives: To study faecal calprotectin (F-calprotectin) levels and antiSaccharomyces cerevisiae antibodies (ASCA) and their associations with disease status and gastrointestinal (Gl) symptoms in axial spondyloarthritis.

Methods: Consecutive patients with a clinical axial spondyloarthritis diagnosis were examined and classified as non-radiographic axial spondyloarthritis (nraxSpA; Assessment of SpondyloArthritis international Society [ASAS] criteria; $n=26$ ) or ankylosing spondylitis (AS; modified New York criteria; $n=45$ ). Only patients without known IBD were included. F-calprotectin and ASCA IgA and IgG antibodies in serum were measured by commercially available enzyme-linked immunosorbent assay kits (Calpro AS; ORGENTEC Diagnostika).

Results: Elevated levels of F-calprotectin $(\geq 50 \mathrm{mg} / \mathrm{kg}$ ) were observed in $15 \%$ of nr-axSpA and $40 \%$ of AS patients (non-significant difference, with reservation for small groups). Overall, worse mean disease activity/disability scores were observed among patients with elevated versus normal F-calprotectin levels (Table), whereas no association was seen between F-calprotectin and Gl symptoms. Similar results remained after exclusion of patients with monoclonal antibody type anti-TNF therapy. Elevated levels of ASCA IgA were observed in $8 \% / 2 \%$ of $\mathrm{nr}$-axSpA/AS patients, and IgG in $28 \% / 26 \%$. Only 2 subjects were ASCA double positive. Neither disease activity/disability measures nor GI symptoms were associated with ASCA status.

\begin{tabular}{|c|c|c|c|c|c|}
\hline & \multirow{2}{*}{$\begin{array}{c}\mathrm{Nr}-\mathrm{axSpA} \\
(\mathrm{n}=26)\end{array}$} & \multirow{2}{*}{$\begin{array}{c}\text { AS } \\
(n=45)\end{array}$} & \multicolumn{2}{|c|}{ F-Calprotectin } & \multirow[t]{2}{*}{$p$-value } \\
\hline & & & $<50 \mathrm{mg} / \mathrm{kg}(\mathrm{n}=38)$ & $\geq 50 \mathrm{mg} / \mathrm{kg}(\mathrm{n}=18)$ & \\
\hline Male sex & 10 (39\%) & 26 (59\%) & $16(42 \%)$ & $10(56 \%)$ & 0.346 \\
\hline Age, years & $45(10)$ & $58(13)$ & $54(13)$ & $55(14)$ & 0.847 \\
\hline Disease duration, years & $18(10)$ & $32(14)$ & $26(14)$ & $31(15)$ & 0.339 \\
\hline HLA-B27 positive, y/n & $24(92 \%)$ & $38(86 \%)$ & $32(84 \%)$ & $17(100 \%)$ & 0.083 \\
\hline ASAS 3m NSAID score & $25(37)$ & $31(36)$ & $21(33)$ & $37(40)$ & 0.221 \\
\hline Antibody anti-TNF, y/n & $10(39 \%)$ & $12(27 \%)$ & $14(36 \%)$ & $4(22 \%)$ & 0.274 \\
\hline VAS global & $41(21)$ & $35(25)$ & $32(25)$ & $45(16)$ & 0.023 \\
\hline VAS pain & $40(23)$ & $37(28)$ & $34(26)$ & $42(23)$ & 0.142 \\
\hline VAS fatigue & $41(28)$ & $39(27)$ & $34(28)$ & $46(21)$ & 0.056 \\
\hline BASDAI & $3.5(1.7)$ & $3.5(2.6)$ & $3.1(2.3)$ & $4.2(2.3)$ & 0.076 \\
\hline BASFI & $1.9(1.4)$ & $3.0(2.9)$ & $2.2(2.2)$ & $3.9(3.1)$ & 0.029 \\
\hline ASDAS-CRP & $2.0(0.8)$ & $2.2(1.1)$ & $1.8(0.9)$ & $2.6(0.9)$ & 0.034 \\
\hline CRP, mg/L & $3.1(3.0)$ & $4.7(4.6)$ & $3.0(2.7)$ & $5.7(5.5)$ & 0.157 \\
\hline F-calprotectin, mg/kg & $45(64)$ & $84(117)$ & $21(13)$ & $172(129)$ & NA \\
\hline ASCA IgA, E/ml & $3.7(7.3)$ & $2.1(1.9)$ & $2.9(5.8)$ & $3.0(3.8)$ & 0.175 \\
\hline ASCA lgG, E/ml & $10(20)$ & $6.5(6.3)$ & $6.9(6.8)$ & $11(24)$ & 0.854 \\
\hline Often stomach pain, $y / n$ & $17(65 \%)$ & $25(56 \%)$ & $23(61 \%)$ & $11(61 \%)$ & 0.967 \\
\hline Frequent defecation, $y / n$ & $7(27 \%)$ & $9(20 \%)$ & $9(24 \%)$ & $5(28 \%)$ & 0.741 \\
\hline Frequent diarrhoea, $\mathrm{y} / \mathrm{n}$ & $12(46 \%)$ & $12(27 \%)$ & $12(32 \%)$ & $8(44 \%)$ & 0.348 \\
\hline
\end{tabular}

$\mathrm{N}(\%)$ or mean (SD). ${ }^{*} \mathrm{Chi}^{2} / \mathrm{Mann}$-Whitney U-test for comparison of categorical/continuous variables between the F-calprotectin groups. Missing data: ASCA IgA/lgG 4\%, F-calprotectin $21 \%$. $\mathrm{y} / \mathrm{n}$, yes/no; 3m, 3 months; NA, not applicable.

Conclusions: Elevated levels of F-calprotectin and ASCA IgG antibodies are both common in axial spondyloarthritis patients without IBD, and elevated F-calprotectin may be a marker of more severe spondyloarthritis. Neither F-calprotectin nor ASCA levels were associated with self-reported GI symptoms.
Disclosure of Interest: T. Olofsson: None declared, E. Mogard: None declared, K. Andréasson: None declared, J. Marsal Grant/research support from: AbbVie, Ferring, Hospira, Consultant for: AbbVie, Ferring, Hospira, MSD, Pfizer, Takeda, Tillotts, UCB, M. Geijer: None declared, L.-E. Kristensen Grant/research support from: Oak Foundation, Consultant for: AbbVie, Celgene, BMS, MSD, Novartis, Pfizer, UCB, E. Lindqvist: None declared, J. Wallman Consultant for: Celgene, Novartis, UCB

DOI: 10.1136/annrheumdis-2017-eular.2391

\section{FRI0446 PREVALENCE AND CHARACTERISTICS OF SPONDYLOARTHRITIS ACCORDING TO ASAS CRITERIA IN PATIENTS WITH INFLAMMATORY BOWEL DISEASE - RESULTS FROM THE SPICE COHORT}

J. Haschka ${ }^{1,2}$, S. Hirschmann ${ }^{3}$, A. Kleyer ${ }^{1}$, M. Englbrecht ${ }^{1}$, J. Zimmermann ${ }^{1}$, F. Faustini $^{1}$, D. Simon ${ }^{1}$, C.P. Figueiredo ${ }^{1}$, A. Cavallaro ${ }^{1,4}$, C. Muschitz ${ }^{2}$, R. Kocijan ${ }^{2}$, H. Resch ${ }^{2}$, R. Atreya ${ }^{3}$, J. Rech ${ }^{1}$, M.F. Neurath ${ }^{3}$, G. Schett ${ }^{1}$ ${ }^{1}$ Department of Internal Medicine 3, University of Erlangen-Nuremberg, Erlangen, Germany: ${ }^{2}$ Medical Department 2, St. Vincent Hospital, The VINFORCE Study Group, Vienna, Austria; ${ }^{3}$ Department of Internal Medicine 1, University of Erlangen-Nuremberg, Erlangen, Germany; ${ }^{4}$ Div. of Rheumatology, Faculdade de Medicina da Universidade de São Paulo, São Paulo, Brazil

Background: Musculoskeletal symptoms are considered as one of the most frequent extra-intestinal manifestation in Inflammatory Bowel Disease (IBD) patients with a prevalence of up to $40 \%$ involving axial and/or peripheral joints. Data on the prevalence of musculoskeletal disease, in particular of $\mathrm{SpA}$ are limited and vary considerably due to different criteria the studies have used to define musculoskeletal disease in IBD patients.

Objectives: To define the prevalence of axial and peripheral spondyloarthritis (SpA) according to Assessment of Spondyloarthritis International Society (ASAS) in patients with Crohn's disease (CD) and ulcerative colitis (UC).

Methods: The SPICE cohort (Spondyloarthritis in Inflammatory Bowel Disease Cohort Erlangen) comprises prospectively recruited colonoscopy- proven Crohn's Disease (CD) or Ulcerative Colitis (UC) patients, who received a pre-defined and standardized musculoskeletal assessment by the rheumatologist. Duration and activity of gastrointestinal and rheumatic disease (axial and peripheral) was documented and fulfillment of ASAS classification criteria for axial and peripheral SpA was tested.

Results: 102 IBD patients (62 with CD and 40 with UC) with a median (IQR) disease of 11.0 (18.0) years were assessed. 38.2\% fulfilled ASAS criteria for SpA with no difference between $\mathrm{CD}$ and UC. ASAS axial SpA criteria were fulfilled by $12 \%$, ASAS peripheral SpA criteria by $31.4 \%$ of the IBD patients. Inflammatory back pain was present in $24.5 \%$ with MRI signs of sacroilitis in $48 \%$ of IBD patients with inflammatory back pain. Disease activity according to ASDAS-CRP was moderate to high in $91 \%$ of the patients with axial SpA. Peripheral arthralgia was present in $71.6 \%$, while arthritis was found in $18.6 \%$ of the IBD patients.

Conclusions: Both major forms of IBD show a similar burden of musculoskeletal disease. More than one third of inflammatory bowel disease patients show axial or peripheral SpA according to ASAS criteria. Peripheral SpA is more commonly found than axial SpA.

References:

[1] Harbord M, Annese V, Vavricka SR, et al. The first European evidence-based consensus on extra-intestinal manifestations in inflammatory bowel disease. $J$ Crohn Colitis 2016; 239-254.

[2] Karreman MC, Luime JJ, Hazes JMW, Weel AEAM. The prevalence and incidence of axial and peripheral spondyloarthritis in inflammatory bowel disease: a systematic literature review and meta-analysis. J Crohn Colitis 2016; 1-12.

Disclosure of Interest: None declared

DOI: 10.1136/annrheumdis-2017-eular.2393

\section{FRI0447 SEVERITY OF SACROILIITIS AND ERYTHROCYTE SEDIMENTATION RATE ARE ASSOCIATED WITH A LOW TRABECULAR BONE SCORE IN YOUNG MALE PATIENTS WITH ANKYLOSING SPONDYLITIS}

K.Y. Kang. Division of Rheumatology, Internal Medicine, Catholic University of Korea, Seoul, Korea, Republic Of

Background: The trabecular bone score (TBS) is a novel method used to evaluate bone microarchitecture. To date, the risk factors associated with a low TBS in AS are unknown and no study has examined the association between TBS and vertebral fracture in ankylosing spondylitis (AS) patients.

Objectives: To examine factors related to a low trabecular bone score (TBS) and the association between TBS and vertebral fracture in patients with (AS)

Methods: One hundred patients (all male, aged $<50$ years) who fulfilled the modified New York criteria for the classification of AS were enrolled. The TBS and bone mineral density (BMD) were assessed using dual-energy $X$-ray absorptiometry (DXA). Clinical variables, inflammatory markers, and the presence of vertebral fracture were also assessed. Spinal radiographic progression was measured using the Stokes AS spine score (SASSS). Multivariate linear regression analysis was performed to identify factors associated with TBS. 
Results: The mean TBS at the lumbar spine was $1.38 \pm 0.13$. The TBS showed a negative correlation with disease duration and inflammatory markers, and a positive correlation with BMD at the lumbar spine, femoral neck, and total hip. It also showed a negative correlation with sacroilitis grade. BMD at the lumbar spine positively correlated with SASSS, whereas TBS showed a negative correlation. A significant decrease in TBS values was observed in patients with spinal radiographic progression $(\mathrm{p}=0.001)$. Multivariate analysis showed that $\mathrm{ESR}$ and sacroilitis were independently associated with TBS $(p=0.006$ and $<0.001$, respectively). Ten patients had morphometric vertebral fractures. The mean TBS was lower in patients with vertebral fracture than in age-matched patients without fracture $(p=0.028)$.

Conclusions: The TBS in young male patients with AS is associated with the ESR and severity of sacroilitis. The TBS may be useful as a tool for assessing osteoporosis in AS.

Disclosure of Interest: None declared

DOI: 10.1136/annrheumdis-2017-eular.1254

\section{FRI0448 EVALUATION OF SUPPURATIVE HIDRADENITIS IN PATIENTS WITH CHRONIC ARTHRITIS TREATED WITH FULL AND TAPERED BIOLOGICAL DISEASE-MODIFYING ANTIRHEUMATIC DRUGS}

L. Valor, D. Hernández-Flórez, T. del Río, J.G. Ovalles B, J. Martínez Barrio, I. Janta, B. Serrano, J.C. Nieto, M. Correyero Plaza, L. Garcia Montoya, C. González, F.J. López-Longo, I. Monteagudo. Hospital General Universitario Gregorio Marañón, Madrid, Spain

Background: Suppurative Hidradenitis (SH) is an inflammatory skin disease which often responds poorly to treatment. It is a disorder of the apocrine glands (axillary, inguinal and anogenital regions) that can result in infection, inflamed nodules, cysts, abscesses and sinus tracts. There is a $1-4 \%$ incidence of $\mathrm{SH}$ in patients with spondyloarthropathies and inflammatory bowel disease, possibly due to innate immune system deregulation. The use of biological disease-modifying antirheumatic drugs (bDMARD), specifically tumor necrosis factor inhibitors, has been useful in cases when other therapies fail.

Objectives: To evaluate the prevalence of $\mathrm{SH}$ using the $\mathrm{SH}$-questionnaire in bDMARD-treated chronic arthritis patients.

Methods: This cross-sectional study included 325 patients diagnosed with chronic arthritis. Patients were recruited consecutively from the Biological Therapy Unit of the Hospital General Universitario Gregorio Marañón and evaluated from January to March of 2015. All patients had been undergoing full or tapered bDMARD treatment for at least 1 year and none had any history of $\mathrm{SH}$. Those patients deemed to be in clinical remission were on tapered bDMARD dosage. All patients self-completed the validated $\mathrm{SH}$-questionnaire (1) which was considered positive when one answer was affirmative and when lesions presented in $>1$ anatomical location. Patient pathologies were subclassified into 2 groups: i) peripheral arthritis (PerAR) which includes rheumatoid arthritis (RA), psoriatic arthritis (PsA) and peripheral spondyloarthropathies (PerSpA); ii) axial spondyloarthropathies $(\mathrm{AxSpA})$. Clinical evaluation was performed by the same physician for all patients. Demographic, clinical and laboratory variables were recorded and disease status was assessed through the relevant clinical index, i.e.DAS28-ESR, DAS28-CRP, SDAI, CDAI, BASDAI, BASFI, ASDAS-CRP.

Results: SH-positive was observed in $25 / 325(7.7 \%$ vs. $92.3 \%)$ patients. Of these 25 patients, $12(48 \%)$ were female and $13(52 \%)$ male. Mean age was 52 years $(\mathrm{SD} \pm 12.9)$ and mean time since diagnosis was 14 years $(\mathrm{SD} \pm 9.3)$. Twenty-four out of 25 patients were undergoing anti-TNF treatment $(E T N=10, G O L=7, A D L=6$, $\mathrm{CTZ}=1$ ). Eighty-four per cent of patients were undergoing full bDMARD dosage with the remaining $16 \%$ on tapered. By subset pathology, $13 \mathrm{SH}$ positives were PerAR type and 12 were AxSpA (5.8\% vs. $11.8 \%, p=0.062$ ). On analysis of PerAR subtypes, we found 6 patients had PsA and 5 RA. Evaluating clinical disease activity, we found $9 / 13$ patients in the PerAR group to be in clinical remission according to DAS28-ESR and CDAI ( $p=0.02$ for both). Additionally, we found only $4 / 12$ patients in remission in the AxSpA group as defined under BASDAI, BASFI and ASDAS-CRP ( $\mathrm{p}=0.006, \mathrm{p}=0.005, \mathrm{p}=0.004$, respectively).

Conclusions: We found more SH-positives in the AxSpA than in the PerAR group, which is consistent with published data. A bDMARD tapered dosage was related to SH-positivity which might be linked to persistent and undetectable chronic inflammation.

References:

[1] Esmann S, et al. Br J Dermatol. 2010 Jul;163(1):102-6.

Disclosure of Interest: None declared

DOI: 10.1136/annrheumdis-2017-eular.4737
FRI0449 ANALYSIS OF THE CANADIAN ADALIMUMAB POST-MARKETING OBSERVATIONAL EPIDEMIOLOGICAL STUDY ASSESSING EFFECTIVENESS IN ANKYLOSING SPONDYLITIS (COMPLETEAS): ASSOCIATION BETWEEN BASELINE EXTRA ARTICULAR MANIFESTATIONS AND PATIENT-REPORTED OUTCOMES

L. Bessette ${ }^{1,2}$, B. Haraoui ${ }^{3}$, M. Khraishi ${ }^{4}$, W. Bensen ${ }^{5}$, V.P. Remple ${ }^{6,7},{ }^{1}$ Faculty of Medicine, Université Laval; ${ }^{2}$ Centre Hospitalier de l'Université Laval, Quebec; ${ }^{3}$ Centre Hospitalier de l'Université de Montréal, Montreal; ${ }^{4}$ Faculty of Medicine, Memorial University of Newfoundland, St. John's; ${ }^{5}$ Division of Rheumatology, McMaster University, Hamilton; ${ }^{6}$ School of Population and Public Health, University of British Columbia, Vancouver; ${ }^{7}$ AbbVie Corp., Montreal, Canada

Background: Ankylosing spondylitis (AS) is an immune mediated inflammatory disease. Although characterized by axial and peripheral joint manifestations, extra articular manifestations (EAMs) are a common clinical feature. EAMs have been found to negatively impact health outcomes including quality of life and work capacity.

Objectives: The aim of this analysis was to describe the prevalence of EAMs at baseline and assess their association with patient-reported outcomes (PROs) in a Canadian routine clinical care setting.

Methods: COMPLETE-AS is an ongoing observational study expected to enroll 1120 AS patients from 60-80 sites across Canada. All patients enrolled between June/2011 - October/2015 were included in this analysis. Eligible patients are antiTNF $\alpha$ naïve adults, with active AS as per the judgment of the treating physician, who require change in current AS treatment. Baseline disease parameters assessed were EAMs (collected from medical chart, physician assessment or patient report), disease activity (BASDAI) and functional status (BASFI); baseline PROs assessed were related to mental health (BDI-II), work limitations (WLQ), and quality of life (QoL; SF-36 Physical (PCS) and Mental (MCS) component summaries). Multivariate linear regression models adjusting for baseline BASDAI and BASFI assessed the impact of EAMs on PROs.

Results: A total of 569 patients were included in the current analysis. Mean (SD) age and duration of disease was $43.3(13.4)$ and 5.9 (9.8) years, respectively. The majority of patients enrolled were male $(57.1 \%)$, Caucasian $(86.1 \%)$, HLA

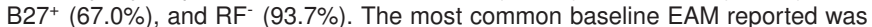
enthesitis $(15.3 \%)$, followed by psoriasis $(13.0 \%)$, inflammatory bowel disease (IBD; 9.1\%), and uveitis (3.2\%). EAM combination 1 (EAM1: all EAMs) and EAM combination 2 (EAM2: excluding psoriasis), was reported by $33.2 \%$, and $23.7 \%$ of patients, respectfully.

Regression analysis adjusting for baseline BASDAI and BASFI, found enthesitis, EAM1, and EAM2 to be significant negative predictors of SF-36 PCS scores $(p<0.05)$. Individual EMAs were not found to impact PROs, except for uveitis, found to be a negative predictor of SF-36 PCS scores for which a statistical trend was identified $(p<0.15)$. No association between EAMs and SF-36 MCS, BD-II or WLQ scores were found.

Conclusions: In a Canadian routine clinical care setting, a substantial proportion of AS patients requiring a change in treatment report EAMs. Patients with EAMs were found to have significant reduction in baseline QoL specifically related to physical functioning.

Acknowledgements: The authors wish to acknowledge JSS Medical Research, Montreal (QC) Canada for statistical analysis, medical writing and editorial assistance during the preparation of this abstract.

Disclosure of Interest: L. Bessette Consultant for: Janssen, Roche, UCB, AbbVie, Pfizer, Celgene, Lilly, Novartis, Speakers bureau: Amgen, BMS, Janssen, Roche, UCB, AbbVie, Pfizer, Merck, Celgene, Lilly, Novartis, B. Haraoui Grant/research support from: AbbVie, Amgen, BMS, Janssen, Pfizer, Roche, and UCB; Speaking engagements: Amgen, BMS, Janssen, Pfizer, and UCB, Consultant for: AbbVie, Amgen, BMS, Celgene, Eli Lilly, Janssen, Merck, Pfizer, Roche, and UCB, Speakers bureau: Amgen, BMS, Janssen, Pfizer, and UCB, M. Khraishi Consultant for: AbbVie, Speakers bureau: AbbVie, W. Bensen Consultant for: Abbvie, Amgen, BMS, Celgene, Janssen, Lilly, Novartis, Merck, Pfizer, Roche, and UCB, Speakers bureau: Abbvie, Amgen, BMS, Celgene, Janssen, Lilly, Novartis, Merck, Pfizer, Roche, and UCB, V. Remple Shareholder of: AbbVie Corp., Employee of: AbbVie Corp.

DOI: 10.1136/annrheumdis-2017-eular.3032

\section{FRI0450 COMMONALITIES AND DIFFERENCES IN DATA COLLECTION ACROSS EUROPEAN SPONDYLOARTHRITIS REGISTRIES}

M.L. Hetland ${ }^{1}$, M. Østergaard ${ }^{1}$, J. Askling ${ }^{2}$, C. Gabay ${ }^{3}$, D. Nordstrom ${ }^{4}$, ${ }^{\text {O. FitzGerald }}{ }^{5}$, M. Hernández Miguel ${ }^{6}$, M. Santos ${ }^{7}$, Z. Rotar ${ }^{8}$, H. Mann ${ }^{9}$, F. lannone ${ }^{10}$, M.J. Nissen ${ }^{3}$, E. Hauge ${ }^{1}$, J. Gomez-Reino ${ }^{11}$, F. Díaz-González ${ }^{12}$, M. Tomsic ${ }^{8}$, K. Pavelka ${ }^{9}$, F. O'Shea ${ }^{5}$, C. Sullivan ${ }^{5}$, M. van de Sande ${ }^{13}$, I.E. van der Horst-Bruinsma ${ }^{13}$, G.J. Macfarlane ${ }^{14}$, G.T. Jones ${ }^{14}$, B. Gudbjørnsson ${ }^{15}$, T.K. Kvien ${ }^{16}$ on behalf of EuroSpA Study Group. ${ }^{1}$ DANBIO, Glostrup, Denmark; ${ }^{2}$ ARTIS, Stockholm, Sweden; ${ }^{3}$ SCQM, Geneva, Switzerland; ${ }^{4}$ ROB-FIN, Helsinki, Finland; ${ }^{5}$ ASRI, Dublin, Ireland; ${ }^{6}$ Biobadaser, Barcelona, Spain; $7^{7}$ reuma.pt, Almada, Portugal; ${ }^{8}$ biorx.si, Ljubljana, Slovenia; ${ }^{9}$ ATTRA, Prague, Czech Republic; ${ }^{10}$ GISEA, Bari, Italy; ${ }^{11}$ Biobadaser, Santiago; ${ }^{12}$ Biobadaser, Santa Cruz de Tenerife, Spain; ${ }^{13} A R C$, Amsterdam, Netherlands; ${ }^{14} B s r b r-A s$, Aberdeen, UK; ${ }^{15}$ ICEBIO, Reykjavik, Iceland; ${ }^{16}$ Nordmard, Oslo, Norway

Background: High quality data from prospective, real life patients with spondy- 